Supplement of Arch. Anim. Breed., 59, 1-8, 2016

http://www.arch-anim-breed.net/59/1/2016/

doi:10.5194/aab-59-1-2016-supplement

(C) Author(s) 2016. CC Attribution 3.0 License.

(c) (1)

Supplement of

\title{
Meta-analysis of intramuscular fatty acid composition of Mediterranean lambs
}

\section{A. Kaić et al.}

Correspondence to: A. Kaić (akaic@agr.hr)

The copyright of individual parts of the supplement might differ from the CC-BY 3.0 licence. 

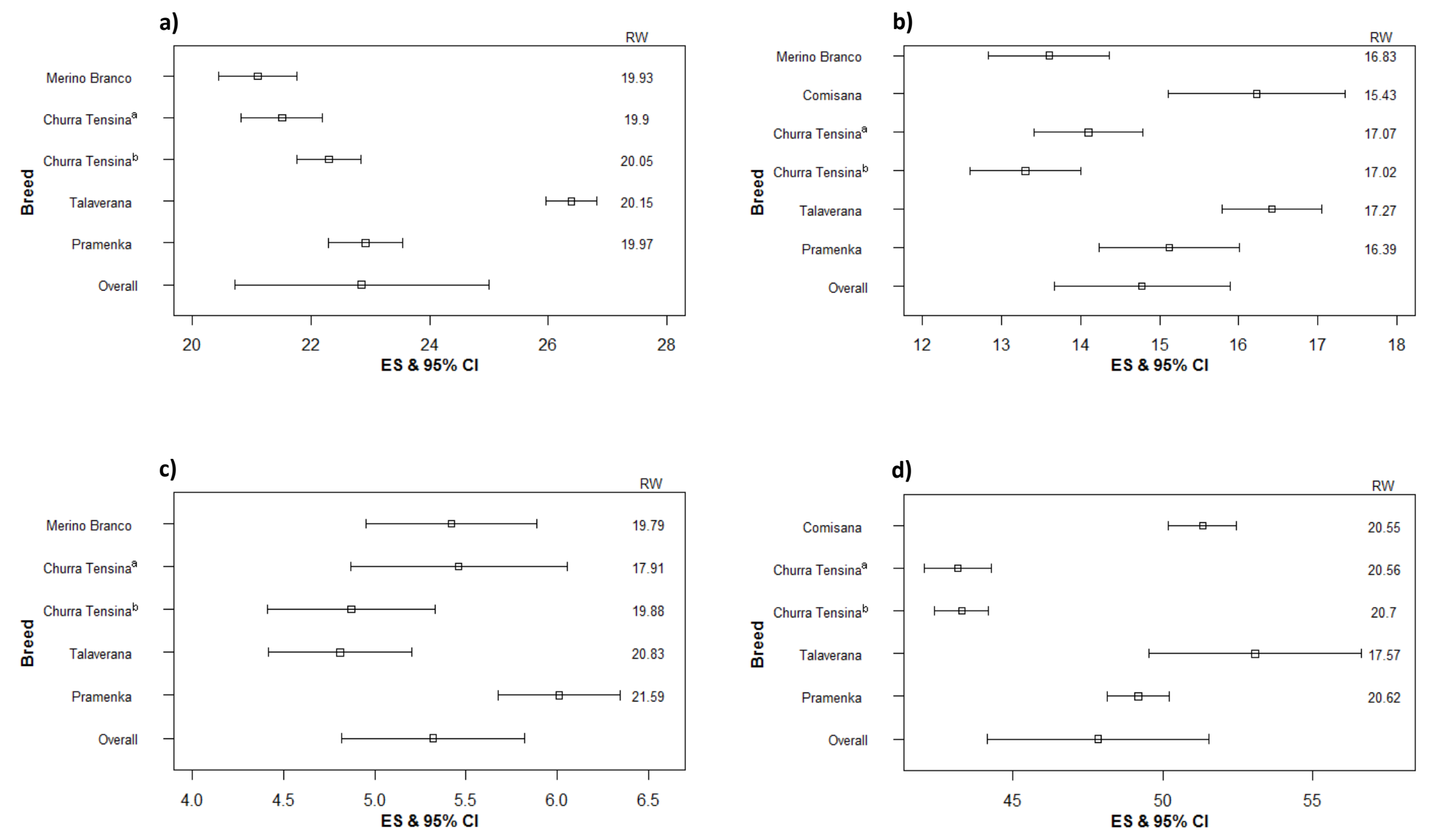

Figure 1. Meta-analysis of C16:0 (a), C18:0 (b), C14:0 (c) and SFA (d). ${ }^{\mathrm{a}, \mathrm{b}}$ : different letters in superscript indicate lambs of the same breed included in different studies; CI: confidence interval; RW: relative weight of the study; Overall: overall pooled result. 

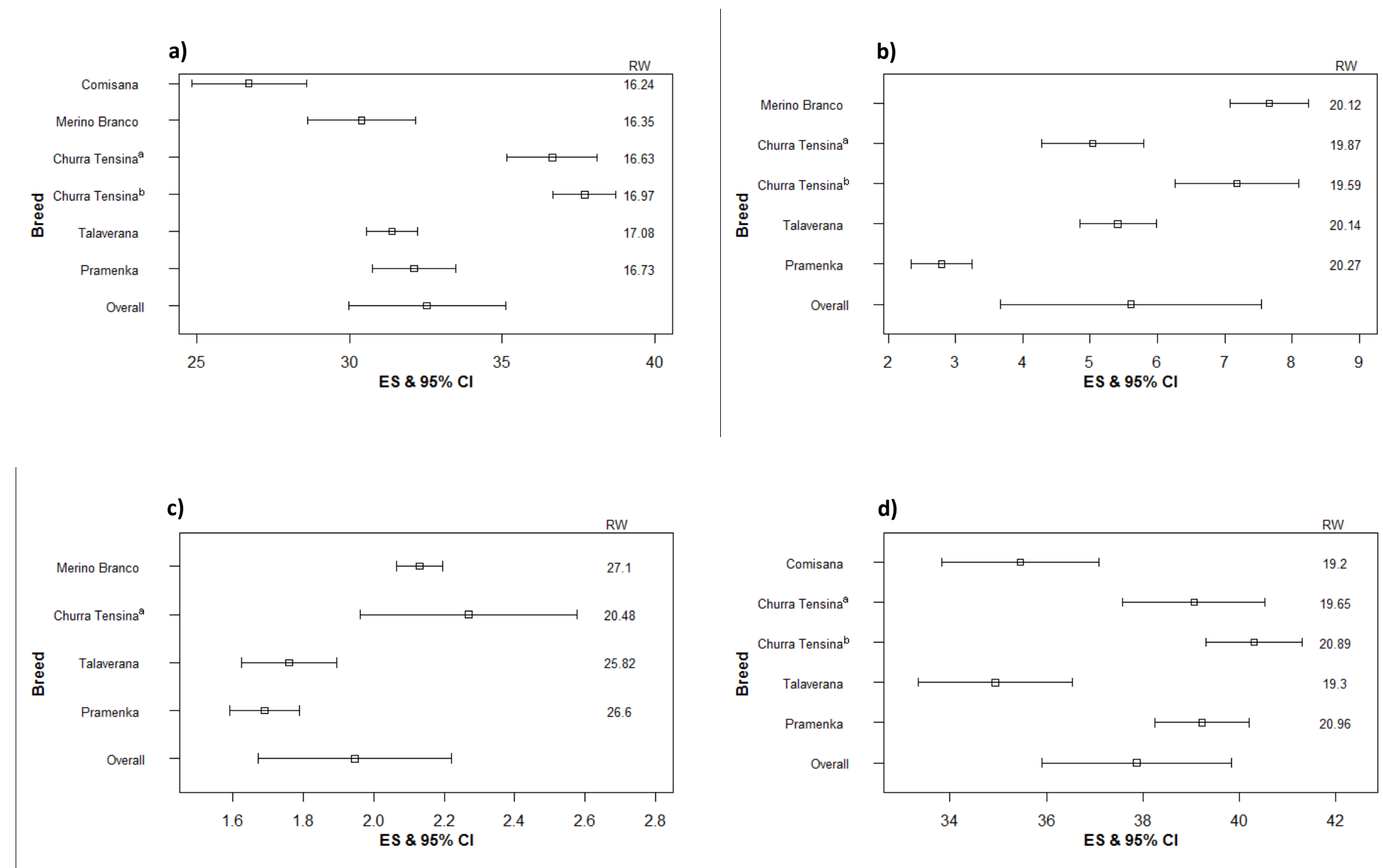

Figure 2. Meta-analysis of C18:1 (a), C18:2 n-6 (b), C18:3 n-3 (c) and MUFA (d). ${ }^{\text {a, b }}$ : different letters in superscript indicate lambs of the same breed included in different studies; ES: effect size; CI: confidence interval; RW: relative weight of the study; Overall: overall pooled result. 

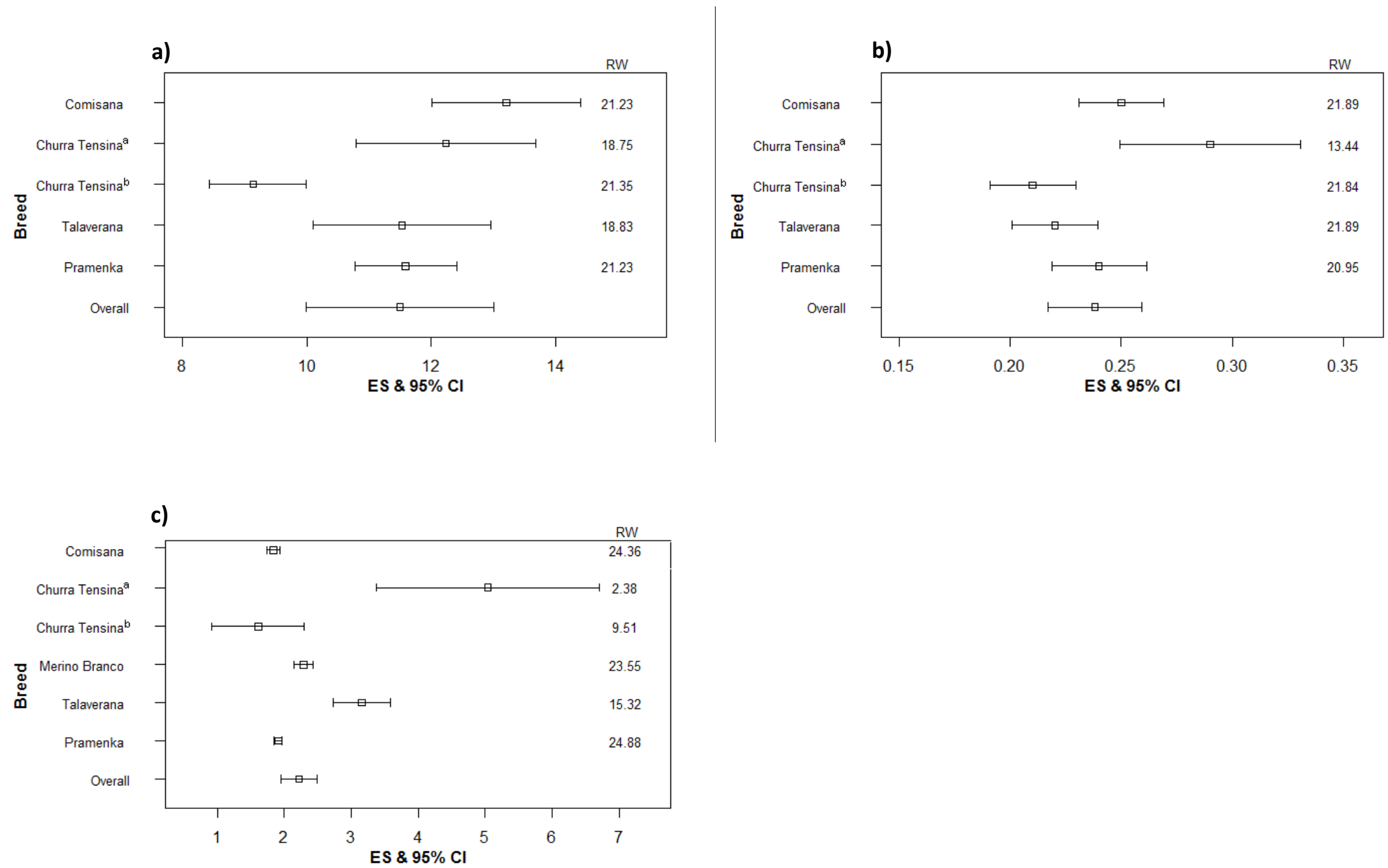

Figure 3. Meta-analysis of PUFA (a), PUFA/SFA ratio (b) and $n-6 / n-3$ ratio (c) ${ }^{\text {a b }}{ }^{2}$ : different letters in superscript indicate lambs of the same breed included in different studies; ES: effect size; CI: confidence interval; RW: relative weight of the study; Overall: overall pooled result. 